\title{
Immunisation coverage and its determinants among children aged 12-23 months in Atakumosa-west district, Osun State Nigeria: a cross-sectional study
}

Elizabeth B. Adedire ${ }^{1,2}$, Ikeoluwapo Ajayi ${ }^{3}$, Olufunmilayo I. Fawole ${ }^{1,3}$, Olufemi Ajumobi ${ }^{1,6}$, Simon Kasasa ${ }^{4}$, Peter Wasswa ${ }^{5^{*}}$ and Patrick Nguku ${ }^{1}$

\begin{abstract}
Background: Routine immunisation (RI) contributes immensely to reduction in mortality from vaccine preventable diseases (VPD) among children. The Nigerian Demographic and Health Survey, 2008 revealed that only $58 \%$ of children in Osun State had received all recommended vaccines, which is far below World Health Organization (WHO) target of $80 \%$. We therefore, assessed Rl uptake and its determinants among children in Atakumosa-west district of Osun State.
\end{abstract}

Methods: Atakumosa-west district has an estimated population of 90,525 inhabitants. We enrolled 750 mothers of children aged 12-23 months in this cross-sectional study. Semi-structured questionnaires were used to obtain data on socio-demographic characteristics, knowledge of mothers on Rl, history of Rl in children and factors associated with full RI uptake. A fully-immunised child was defined as a child who had received one dose of Bacillus-CalmetteGuerin, three doses of Oral-Polio-Vaccine, three doses of Diptheria-Pertusis-Tetanus vaccine and one dose of measles vaccine by 12 months of age. We tested for the association between immunisation uptake and its likely determinants using multivariable logistic regression at 0.05 level of significance and $95 \%$ confidence Interval (Cl).

Results: Mean $\pm(S D)$ age of the mothers and children were $27.9 \pm 6.1$ years and $17.2 \pm 4.0$ months, respectively. About $94 \%$ (703/750) of mothers had received antenatal care (ANC) and $63.3 \%$ (475) of the children possessed vaccination cards. Seventy-six percent (571/750) had good knowledge of RI and VPD. About 58 \% (275/475) of children who possessed vaccination card were fully-immunised. Mothers antenatal care attendance $(a \mathrm{OR}=3.3$, $95 \% \mathrm{Cl}=1.1-8.3)$, maternal tetanus toxoid immunisation ( $\mathrm{aOR}=3.2,95 \% \mathrm{Cl}=1.1-10.0)$ access to immunisation information $(\mathrm{aOR}=1.8,95 \% \mathrm{Cl}=1.1-2.5)$ and mothers having good knowledge of immunisation $(\mathrm{aOR}=2.4$, $95 \% \mathrm{Cl}=1.6-3.8)$ were significant determinants of full immunisation.

Conclusions: Routine immunisation uptake was still below WHO target in the study area. Encouraging mothers to attend antenatal care and educational interventions targeted at rural mothers are recommended to improve vaccination status of children in the rural communities.

Keywords: Immunisation coverage, Children, Rural district, Southwest Nigeria

Abbreviations: ANC, Antenantal care; BCG, Bacille Calmette Guerin; DEFF, Design effect; DPT, DiptheriaPertusis-Tetanus; EPI, Expanded program on immunisation; HBV, Hepatitis B vaccine; OPV, Oral polio vaccine; $\mathrm{RI}$, Routine immunisation; $\Pi$, Tetanus toxoid; VPD, Vaccine preventable diseases; WHO, World Health Organisation

\footnotetext{
* Correspondence: wasswakit@yahoo.co.uk

${ }^{5}$ African Field Epidemiology Network, Plot 42, Lugogo By-Pass, Kampala,

Uganda

Full list of author information is available at the end of the article
} 


\section{Background}

Immunisation remains one of the most cost-effective public health strategies to reduce morbidity and mortality associated with vaccine preventable diseases. Routine immunisation (RI) has contributed immensely to significant reduction in mortality from these vaccine preventable diseases among children. Globally, it is estimated that about two to three million deaths occurs yearly as a result of vaccine preventable diseases (VPD) with approximately 1.5 million deaths among under-five children [1].

The World Health Organisation (WHO) established the expanded programme on immunisation (EPI) in 1974, with the goal of ensuring full accessibility of routine immunisation vaccines to all children. According to the EPI, a child should receive Bacillus Calmette Guerin (BCG), three doses of oral polio vaccine (OPV) and Diptheria Pertusis Tetanus (DPT), and measles vaccines by 12 months of age to ensure maximum protection against VPDs. Receipt of these vaccines at the recommended ages and intervals will provide the children adequate protection from VPDs [2].

Despite significant gains with routine immunisation coverage over the years, millions of children living in developing countries are not fully immunised, exposing them to disabilities or premature death. In 2014, over $60 \%$ of the 18.7 million infants who were not fully vaccinated lived in ten countries including India, Nigeria, Democratic Republic of Congo, Ethiopia, Iraq, Pakistan, Philippines, Indonesia, Uganda and South Africa [1].

In Nigeria, VPDs are attributable for $22 \%$ of childhood deaths amounting to over 200,000 deaths per year [3]. Routine immunisation coverage has remained low in many parts of Nigeria. Even though vaccines are provided free of charge by the government, coverage rates for routine immunisation antigens in many parts of Nigeria still fall below $50 \%$ [4-7]. According to the 2008 Nigerian Demographic and Health Survey Report, only $57.8 \%$ of children aged 12-23 months in Osun State were fully immunised, far below the WHO target of $80 \%$ [8]. The situation is worse in the rural areas as children in these areas were twice less likely to receive full doses of RI vaccination than those in urban areas [8]. Studies have shown that uptake of immunisation services depends not only on provision of these services but other factors related to maternal knowledge, geographical accessibility and many other socio-demographic characteristics [8-10].

Rural communities represent highly marginalised areas in terms of distribution and access to health care interventions including immunisation services. This underscores the need to determine immunisation coverage rates and the factors influencing uptake of RI services in these marginalised areas. Thus, we conducted a study to assess immunisation coverage rates and to identify the factors associated with vaccination status of children $12-23$ months in a rural district in south-western Nigeria.

\section{Methods \\ Study setting}

We conducted this study in Atakumosa-west district which is a predominantly rural district in Osun State, south-western Nigeria. It had an estimated population of 90,525 inhabitants based on the 2007 population census [11]. Atakumosa-west district is made up of eleven wards with about 170 widely distributed settlements. The Yorubas are the main ethnic tribe residing in the area most of whom are farmers. There are 27 primary health centers and two comprehensive health centers all of which provide routine immunisation.

\section{Study design}

We conducted a community-based cross-sectional study between September and October 2013. Mothers of children 12-23 months old who were resident in the district at the time of the survey were interviewed. At the time of the study, children 12-23 months of age were considered eligible for sampling.

\section{Sample size determination}

We used the method in the WHO immunization coverage cluster survey reference manual to determine the sample size based on a full immunisation coverage of $57.8 \%$ [9], significance level of $5 \%$ corresponding to a standard normal deviate $(\mathrm{z})$ of 1.96 , precision of $5 \%$ and design effect (DEFF) of 2 and obtained a minimum sample size of 750 children [12].

\section{Sampling procedure}

We used a two-stage cluster sampling technique to sample eligible children. At stage one (selection of clusters), we selected 30 clusters from the available 170 clusters based on probability- proportional- to- size of the population. In stage two (selection of households), we selected 25 households from each of the 30 clusters selected at stage one. The first household in each cluster was selected randomly and subsequent households were selected contiguously in the right direction until the required number of households for that cluster was achieved. From each selected household, one eligible child was selected. If a selected household had more than one eligible child, only one was randomly selected. If a selected household had no eligible child, the next contiguous household was visited and one eligible child selected. We sampled an equal number of children from each of the 30 clusters [12]. Thus, 25 children were sampled per cluster, giving a total sample size of 750 children. 


\section{Data collection}

Data for the study were collected by 15 trained community health extension workers using standardised structured and pretested interviewer-administered questionnaires. The questionnaires were administered in 'Yoruba'; the predominant spoken language and back translated to English to avoid any ambiguity. Data collected include socio-demographic characteristics of mothers and children, knowledge of mothers regarding routine immunisation, vaccination status of children and reasons for incomplete or non-vaccination. If a card was available, the interviewer recorded the vaccination information and dates of each vaccination received by the child. If a child had never received a vaccination card, or the mother was unable to show the card to the interviewer, the vaccination information for the child was based on the mother's report.

\section{Knowledge of respondents on RI and VPDs}

To assess the knowledge of mothers, responses were scored using six questions on various aspects of routine immunisation. The questions assessed respondent's ability to state: the correct purpose of immunisation, correct age a child should receive second dose of RI vaccinations, last dose of RI vaccines, total number of visits a child should make to the health facility to receive all recommended doses, at least three symptoms of vaccine preventable diseases and at least three vaccine preventable diseases. Each correct response was scored one point while each wrong response was scored zero. Mothers who scored three points and below were graded as having poor knowledge while those who scored four points and above were graded as having good knowledge. This scoring system is similar to that used in determining vaccination coverage in Nigeria [9].

\section{Outcome variable \\ Vaccination status of children}

Based on the type and doses of RI antigens received, we categorized the children as fully immunised, partially immunised, or un-immunised. We defined a "fully immunised child" as a child who had received one dose of BCG, three doses of OPV (excluding OPV given at birth), three doses of DPT vaccine and one dose of measles vaccine by 12 months of age; "partially immunised child" a child who missed at least any one of the above doses; "un-immunised child" a child who had not received any vaccine by 12 months of age [13].

\section{Data analysis}

Data were entered, cleaned and edited for inconsistencies before analyzing with Epi info version 7. Descriptive analysis was done and the results were summarized as frequencies and proportions for categorical variables and means and standard deviations (SD) for continuous variables. During bivariate analysis, associations between categorical variables were assessed using the Chi square test at $95 \%$ Confidence Interval (CI). A multivariable logistic regression model with full immunisation status as dependent variable was built to rule out possible confounders. All analyses were done at $95 \% \mathrm{CI}$ and 0.05 level of significance.

\section{Results \\ Socio-demographic characteristics of mothers and children}

A total of 750 mothers were interviewed with mean age (SD) of 27.9 (6.1) years. Fifty-five percent of mothers were $20-29$ years old, $3.1 \%$ had no formal education, and $94.1 \%$ were married. The mean age (SD) of the children was 17.2 (4.0) months; age of children ranged from 12 to 23 months and about half $(50.4 \%)$ of the children were males (Table 1$)$.

\section{Vaccination coverage rate}

The fully vaccinated coverage rate obtained by mothers' recall was $74.4 \%$ and fully vaccinated coverage rate obtained by immunisation card for all the antigens was $57.9 \%$. The proportion of children vaccinated with antigens given at birth and six weeks of age were more than the proportions of children vaccinated with antigens given at later ages (Table 2).

\section{Vaccination status of children 12-23months}

Of the 750 children, 475 possessed vaccination cards, indicating a vaccination card retention rate of $63.3 \%$. As shown in Fig. 1. Using mothers' recall, 558 (74.4 \%) of the children were fully-vaccinated, $192(20.8 \%)$ were partially-vaccinated, while $36(4.8 \%)$ were non-vaccinated. However, based on immunisation cards, 275 (57.9 \%) of the children were fully immunised while 200 (42.1\%) were partially immunised (Fig. 1). On comparison of the mothers assessment of completeness of vaccination with card assessment using Kappa's statistics, the number of observed agreements was 331.0 (69.7\% of the observations) and the number of agreements expected by chance was 258.3 (54.4\% of the observations), giving a kappa of 0.336 [SE of kappa $=0.041,95 \%$ CI; $0.256-0.416]$. The agreement between the mothers assessment and card assessment was low, thus further analysis were done using information from the cards.

\section{Determinants of immunisation status}

Table 3 shows the bivariate and multivariate analysis of factors associated with full immunisation status using the information obtained from the vaccination cards. Five factors namely; mothers age $>35$ years, antenatal care (ANC) visits by mother, maternal tetanus toxoid 
Table 1 Socio-demographic characteristics of mothers and children in rural Atakumosa-west district, Osun State, Nigeria- September 2013

\begin{tabular}{|c|c|c|}
\hline Variables/characteristics & Frequency $(n=750)$ & Proportion (\%) \\
\hline \multicolumn{3}{|l|}{ Age-group (years) } \\
\hline$<20$ & 39 & 5.2 \\
\hline $20-29$ & 415 & 55.3 \\
\hline $30-39$ & 251 & 33.5 \\
\hline$\geq 40$ & 45 & 6.0 \\
\hline \multicolumn{3}{|l|}{ Education } \\
\hline No formal education & 23 & 3.1 \\
\hline Completed primary & 172 & 22.9 \\
\hline Completed secondary & 402 & 55.3 \\
\hline Post secondary & 153 & 20.4 \\
\hline \multicolumn{3}{|l|}{ Marital Status } \\
\hline Married & 706 & 94.1 \\
\hline Single & 27 & 3.7 \\
\hline Divorced/widowed & 17 & 2.2 \\
\hline \multicolumn{3}{|c|}{ Children age-group (months) } \\
\hline $12-15$ & 133 & 23.5 \\
\hline $16-19$ & 170 & 30.1 \\
\hline $20-23$ & 262 & 46.4 \\
\hline \multicolumn{3}{|l|}{ Sex of child } \\
\hline Male & 372 & 49.6 \\
\hline Female & 378 & 50.4 \\
\hline \multicolumn{3}{|l|}{ Childs' birth order } \\
\hline 1 & 233 & 31.3 \\
\hline 2 & 216 & 29.0 \\
\hline$\geq 3$ & 296 & 39.7 \\
\hline \multicolumn{3}{|l|}{ Place of birth } \\
\hline Health facility & 611 & 81.5 \\
\hline Non-health facility & 139 & 18.5 \\
\hline
\end{tabular}

immunisation, maternal knowledge of routine immunisation and access to immunisation information in last 12 months were significantly associated with full immunisation in bivariate analysis; however following multivariate logistic regression; mothers who accessed ANC $(\mathrm{aOR}=3.3,95 \% \mathrm{CI}=1.2-8.3)$, mothers who had at least one dose of tetanus toxoid immunisation $(\mathrm{aOR}=3.2,95 \% \mathrm{CI}=1.1-10.0)$, mothers having good knowledge of immunisation $(\mathrm{aOR}=2.4,95 \% \mathrm{CI}=1.6-3.8)$ and having access to immunisation information in the last 12 months $(\mathrm{aOR}=1.8,95 \% \mathrm{CI}=1.1-2.5)$ were significant predictors of full immunisation status.

\section{Discussion}

We assessed the immunisation coverage rate for routine immunisation and its determinants in rural district of
Table 2 Vaccination coverage for routine immunisation antigens in rural Atakumosa-west district, Osun State, Nigeria-September 2013

\begin{tabular}{|c|c|c|}
\hline $\begin{array}{l}\text { Routine } \\
\text { immunisation } \\
\text { antigens }\end{array}$ & $\begin{array}{l}\text { Coverage by mothers' } \\
\text { recall } n,(\%) ;[95 \% \mathrm{Cl}] \\
n=750\end{array}$ & $\begin{array}{l}\text { Coverage by immunisation } \\
\text { card } n,(\%) ;[95 \% \mathrm{Cl}] \\
n=475\end{array}$ \\
\hline \multicolumn{3}{|c|}{ Antigens administered at birth } \\
\hline $\mathrm{BCG}$ & $687(91.6)[89.3-93.4]$ & $406(85.5)[81.9-88.5]$ \\
\hline OPV 0 & $693(92.4)[90.2-94.2]$ & $395(83.2)[79.4-86.4]$ \\
\hline HBV 1 & $677(90.3)[87.9-92.3]$ & $392(82.5)[78.7-85.7]$ \\
\hline \multicolumn{3}{|c|}{ Antigens administered at 6 weeks } \\
\hline OPV 1 & $681(90.8)[88.5-92.3]$ & $386(81.3)[77.4-84.6]$ \\
\hline DPT 1 & $694(92.5)[90.4-94.3]$ & $400(84.2)[80.5-87.3]$ \\
\hline HBV 2 & $676(90.1)[87.7-92.1]$ & $382(80.4)[76.5-83.8]$ \\
\hline \multicolumn{3}{|c|}{ Antigens administered at 10 weeks } \\
\hline OPV 2 & $655(87.3)[84.7-89.6]$ & $362(76.2)[72.1-79.9]$ \\
\hline DPT 2 & $659(87.8)[85.3-90.1]$ & $370(77.9)[73.8-81.5]$ \\
\hline \multicolumn{3}{|c|}{ Antigens administered at 14 weeks } \\
\hline OPV 3 & $636(84.8)[81.9-87.3]$ & $339(71.4)[67.0-75.4]$ \\
\hline DPT 3 & $638(85.1)[82.3-87.5]$ & $352(74.1)[69.9-77.9]$ \\
\hline HBV 3 & $615(82.0)[79.0-84.7]$ & $348(73.3)[69.0-77.1]$ \\
\hline \multicolumn{3}{|c|}{ Antigens administered at 9 months } \\
\hline Measles & $622(82.9)[80.0-85.5]$ & $317(66.7)[62.3-70.9]$ \\
\hline Yellow fever & $597(79.6)[76.5-82.4]$ & $311(65.5)[60.9-69.7]$ \\
\hline $\begin{array}{l}\% \text { Fully } \\
\text { vaccinated }\end{array}$ & $558(74.4)$ & $275(57.9)[53.3-62.4]$ \\
\hline
\end{tabular}

Atakumosa-west Nigeria. The coverage rates for antigens given at birth (BCG, OPV0, and Hepatitis B Virus 1 [HBV]) were relatively higher compared with those given at later ages (measles and yellow fever vaccines). Based on mothers recall, $74.4 \%$ of the children were fully vaccinated while only $57.9 \%$ of children were fully vaccinated based on immunisation card assessment. We found that more than three-quarters of the mothers of children $12-23$ months had good knowledge on routine immunization; however misconception still existed among a few. The factors found to positively influence completion of recommended schedule of routine immunisation included mothers' attendance of antenatal care, mothers receipt of at least one dose of tetanus toxoid immunisation, mothers having good knowledge of immunisation and having access to information on routine immunisation.

Mothers are influential and known to play important roles in the vaccinations of their children. Majority of the mothers had good knowledge, which is similar to findings in rural south-western Nigeria which showed that about four-fifth of respondents had good knowledge on routine immunisations [9]. About three-quarters of mothers knew the purpose of routine immunisation; to prevent childhood 


\section{Vaccination status of children 12-23month}

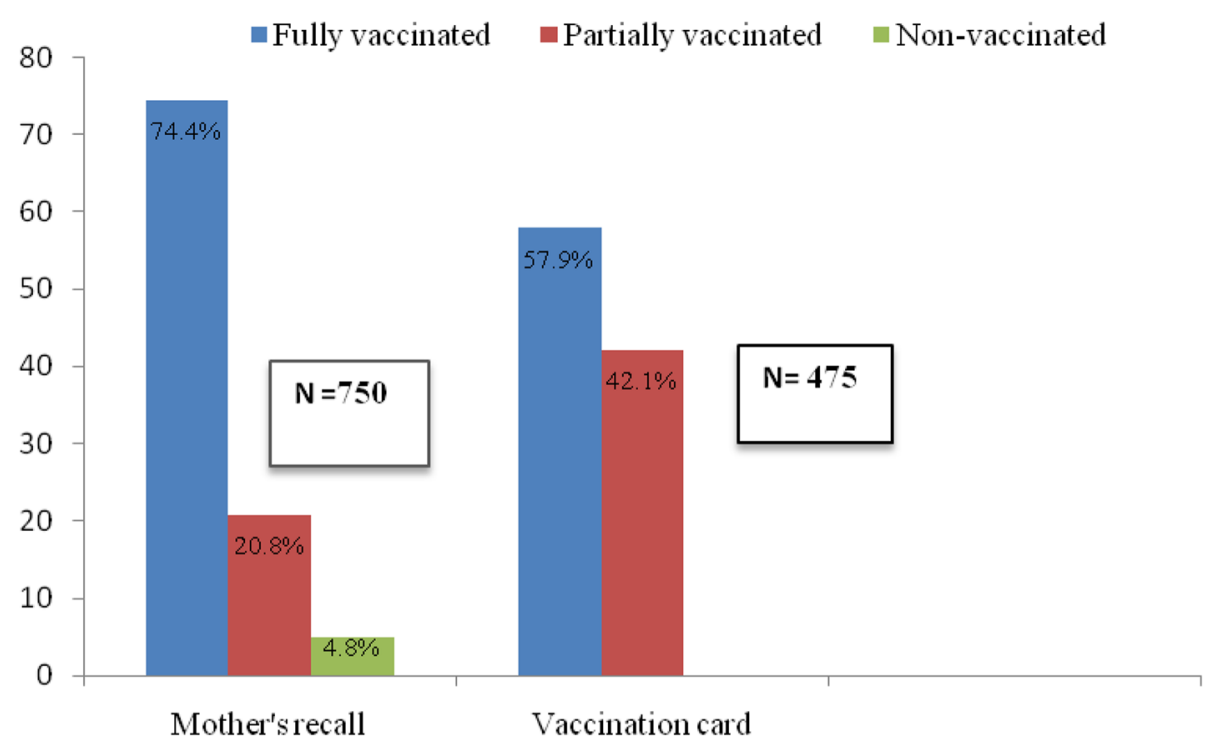

Fig. 1 Vaccination status of children 12-23 months in rural Atakumosa-west district, Nigeria- September 2013

illnesses. This is similar to findings in some parts of Ethiopia [14]. More than $70 \%$ of the mothers knew the correct age at which the different vaccines were given with a higher proportion knowing the correct age for the first and last doses. This good knowledge level was consistent with other studies in Nigeria and other African countries [9, 14, 15].

In this study, the target coverage rate of $80 \%$ for all antigens was achieved for antigens given at birth. These vaccines (BCG, OPV0, and HBV1) had higher coverage rates when compared with others given after birth. This could be due to the fact that many of the children were delivered in health facilities and obtained these vaccines before leaving the health facilities. This finding is similar to those in south- western Nigeria and Istanbul [10, 15]. The lowest coverage rates were recorded for measles and yellow fever vaccines, reflecting poor compliance with vaccines administered late in infancy. This finding corroborates with that in Oyo State Nigeria [16]. A plausible reason is the relatively long period between the first dose of vaccines and those of measles and yellow fever which may make mothers forget to return for appointments for these vaccines, moreover when concerns about child care and survival may not be as high as those of the newborn.

Our study revealed that $74.4 \%$ of children were fully immunised by mothers recall alone, while only $57.9 \%$ were fully immunised by vaccination card; this difference could be as a result of inability of mothers to recall actual doses of vaccines and social desirability biases which may lead to overestimation of vaccines received by the children.
In identifying the determinants of complete immunisation, our study relied on card assessment. This was because when we compared the mothers' assessment of completeness of vaccination with card assessment using Kappa's statistics, the number of observed agreements was low. This increased the accuracy of our findings as suggested by some authors that relied on mothers' assessment of vaccination status $[9,17]$. About $4 \%$ of children in this district had never been vaccinated based on reports given by their mothers. However, the true proportion in the community was likely to be higher. This finding highlights the importance of tracing and identifying missed children, especially in the final push to eradicate poliomyelitis as clusters of unimmunised children may prevent the interruption of wild polio virus.

Maternal health care utilization indices such as mother's attendance of antenatal care and maternal tetanus toxoid immunisation status were found to be predictors of completion of immunisation schedule; these factors have been previously demonstrated by several other studies $[14,18-20]$. These findings suggest the need to sensitize women to seek health care services during pregnancy and also promote utilisation following childbirth.

In addition, several studies have demonstrated that maternal knowledge on vaccines and routine immunisation improves vaccination uptake $[14,21]$. This study also identified this association, as mothers with good knowledge of routine immunisation were found to be twice as likely to fully immunise their children. The finding that having access to information on routine immunisation influences uptake is pertinent as it 
Table 3 Determinants of immunisation status of children 12-23 months in rural Atakumosa-west district, Osun State, Nigeria-September 2013

\begin{tabular}{|c|c|c|c|c|c|c|}
\hline Variables & Fully immunised $n=275$ & Not fully immunised $\mathrm{d} n=200$ & COR $[95 \% \mathrm{Cl}]$ & $p$-value & aOR $[95 \% \mathrm{Cl}]$ & $p$-value \\
\hline \multicolumn{7}{|c|}{ Age of mother (years) } \\
\hline$<35$ & $238(60.2)$ & $157(39.8)$ & 1 & & 1 & \\
\hline$\geq 35$ & $37(46.3)$ & $43(53.7)$ & $1.8[1.1-2.9]$ & 0.02 & $1.1[0.9-1.3]$ & 0.15 \\
\hline \multicolumn{7}{|l|}{ Education } \\
\hline No & $64(53.3)$ & $56(46.7)$ & 1 & & & \\
\hline Formal/primary & $211(59.4)$ & $144(40.6)$ & $0.8[0.5-1.2]$ & 0.24 & & \\
\hline \multicolumn{7}{|c|}{ Secondary/higher } \\
\hline \multicolumn{7}{|l|}{ Child sex } \\
\hline Female & $134(55.8)$ & $106(44.2)$ & 1 & & & \\
\hline Male & $141(60.0)$ & $94(40.0)$ & $0.7[0.6-1.2]$ & 0.35 & & \\
\hline \multicolumn{7}{|l|}{ Child birth order } \\
\hline$\geq 3$ & $106(55.2)$ & $86(44.8)$ & 1 & & & \\
\hline$<3$ & $169(59.7)$ & $114(40.3)$ & $0.8[0.5-1.1]$ & 0.32 & & \\
\hline \multicolumn{7}{|l|}{ Place of birth } \\
\hline Health facility & $235(59.1)$ & $163(40.9)$ & 1 & & & \\
\hline $\mathrm{Home} \mathrm{TBA}^{\dagger}$ & $40(51.9)$ & $37(48.1)$ & $1.3[0.8-2.2]$ & 0.25 & & \\
\hline \multicolumn{7}{|l|}{ Antenatal care } \\
\hline No & $7(33.3)$ & $14(66.7)$ & 1 & & 1 & \\
\hline Yes & $268(59.1)$ & $186(40.9)$ & $2.8[1.1-8.1]$ & 0.02 & $3.3[1.2-8.3]$ & 0.03 \\
\hline \multicolumn{7}{|c|}{ Health facility within $5 \mathrm{~km}$ to residence } \\
\hline Yes & $248(59.1)$ & $172(40.9)$ & 1 & & 1 & \\
\hline No & $27(49.1)$ & $28(50.9)$ & $0.7[0.4-1.2]$ & 0.16 & $1.6[0.9-2.8]$ & 0.11 \\
\hline \multicolumn{7}{|c|}{ Maternal tetanus toxoid } \\
\hline None & $5(27.8)$ & $136(72.2)$ & 1 & & 1 & \\
\hline At least a dose & $270(59.1)$ & $187(40.9)$ & $3.8[1.3-1.7]$ & 0.001 & $3.2[1.1-10.0]$ & 0.04 \\
\hline \multicolumn{7}{|c|}{ Maternal knowledge on Rl } \\
\hline Poor & $40(40.4)$ & $59(59.6)$ & 1 & & 1 & \\
\hline Good & $235(62.5)$ & $141(37.5)$ & $2.4[1.5-3.8]$ & $<0.001$ & $2.4[1.6-3.8]$ & 0.00 \\
\hline \multicolumn{7}{|c|}{ Access to immunisation information in last 12 months } \\
\hline No & $71(68.3)$ & 33(31.7) & 1 & & 1 & \\
\hline Yes & $204(54.9)$ & $167(45.1)$ & $1.8[1.1-2.9]$ & 0.01 & $2.5[1.1-2.5]$ & 0.02 \\
\hline
\end{tabular}

$\mathrm{TBA}^{\dagger}$ : Traditional birth attendant

Text in bold denotes statistically significant results

emphasizes the fact that information reinforces knowledge which eventually leads to utilisation and uptake of health services including immunisation. This finding had also been previously demonstrated in a similar study in Uganda [20].

Geographical accessibility to health facilities offering routine immunisation services is known to be a major determinant of immunisation coverage in many areas of Nigeria and most parts of sub-Saharan Africa, as demonstrated by other studies $[18,20]$. However, similar to findings by Jackrati et al. in Mozambique, our study did not also find this association [22]. Many studies have also demonstrated the association between place of delivery of child and immunization uptake $[14,16]$. However, this study did not find a significant association between these two factors. It is possible that the health facilities in these areas were not actively promoting vaccination of children after delivery but our study could not verify this assertion because we did not explore health system factors.

One of the strength of this study is that the study was community-based. Data were collected following household visits by trained community health workers ensuring 
accuracy of information given. Also, the very high vaccination card retention rate of $63.3 \%$ which was higher than reported in the past as national average of $26.1 \%$ [8] gave a fairly accurate assessment on the immunisation coverage in this district.

However the study has some limitations. Firstly, the effect of health system factors as well as immunisation service delivery related factors including vaccine availability, health care personnel and logistics which are known to have an influence on uptake of immunisations were not explored. Secondly, the socioeconomic and paternal factors that may influence completion of immunisation were not assessed. However despite these limitations, the study adds to the body of knowledge on immunisation uptake in rural areas and the results can be generalised to other communities in southwestern Nigeria. Thus it provides useful information to program managers and policy makers to improve immunisation coverage and thereby reduce childhood morbidity and mortality.

\section{Conclusions}

The full immunisation coverage rate in the rural district of Osun State was below the target of at least $80 \%$ of all antigens by 12 months of age. The factors that determined full immunisation status included mothers' attendance of antenatal care, mothers' receiving tetanus toxoid immunisation, having access to routine immunisation information as well as having good knowledge on routine immunisation. We recommend that effort should be made to increase maternal health care utilisation such as antenatal care utilisation and uptake of tetanus toxoid immunisation by mothers. Health care providers need to conduct health education activities on the benefits and schedule of immunisation to mothers, to improve their knowledge on routine immunisation.

\section{Additional file}

Additional file 1: Data set on immunisation coverage survey in Atakumosa west LGA, Osun State Nigeria. (XLS 1246 kb)

\section{Acknowledgements}

We acknowledge the support of the Director of Health Atakumosa-West District and health workers who assisted with data collection. We acknowledge the technical and logistical support provided by the African Field Epidemiology Network (AFENET) during implementation of this study and developing of this manuscript. This study was made possible by the support of the American people through the United States Agency for International Development (USAID). The contents of this report are the sole responsibility of the authors and do not necessarily reflect the views of USAID or the United States Government.

\section{Funding}

The funding for this study was provided by United States Agency for International Development (USAID) through a cooperative agreement between the Centers for Disease Control and Prevention (CDC), Atlanta and the African Field Epidemiology Network (AFENET). The funder had no role in design of the study, data collection and analysis, interpretation of data or writing the manuscript.

\section{Availability of data and materials}

The datasets supporting the conclusions of this article are included within the article and the attached Excel ${ }^{\mathrm{TM}}$ additional supporting file (Additional file 1: Immunisation Study Data.xlsx).

\section{Authors' contributions}

EA designed the study, analyzed the data and drafted the manuscript, IA and OA guided the design of the study, provided necessary reference materials and reviewed draft manuscript, SK supported data analysis and also reviewed the draft manuscript, PN, OF and PW reviewed drafts of the manuscript. All authors read and approved the final manuscript.

Competing interests

The authors declare that they have no competing interests.

Consent for publication

Not applicable.

Ethics approval and consent to participate

Ethical clearance for the study was obtained from the Ethical Committee of Osun State Ministry of Health (OSHREC/PRS/569T/1). Data was anonymised and written informed consent was obtained from each respondent before they were interviewed. Confidentiality of the respondents was assured and maintained during and after the study.

\section{Author details}

${ }^{1}$ Nigeria Field Epidemiology and Laboratory Training Programme, Abuja, Nigeria. ${ }^{2}$ LAUTECH Teaching Hospital, Osogbo, Osun State, Nigeria. ${ }^{3}$ Epidemiology and Medical Statistics Department, University of Ibadan, Ibadan, Nigeria. ${ }^{4}$ School of Public Health, Makerere University College of Health Sciences, Kampala, Uganda. ${ }^{5}$ African Field Epidemiology Network, Plot 42, Lugogo By-Pass, Kampala, Uganda. ${ }^{6}$ National Malaria Elimination Programme, Federal Ministry of Health, Abuja, Nigeria.

Received: 2 October 2015 Accepted: 20 June 2016

Published online: 30 August 2016

\section{References}

1. World Health Organization (WHO). United Nations Children's Fund (UNICEF). Global immunization data. Geneva: WHO; 2014. Jul. Available from: http://www. who.int/immunization/monitoring_surveillance/global_immunization_data.pdf.

2. National Primary Health Care Development Agency. National Immunisation Policy 2009. Available at http://www.jhsph.edu/research/ centers-and-institutes/ivac/resources/Nigeria-NRISP-Technical-Policy.pdf Accessed 9th December 2013.

3. United State Agency for International Development (USAID) for Africa, Immunisation Basics. Strengthening Routine Immunisation Services and Sustainable Financing for Immunisation 2009. http://www.immunisationbasics. jsi.com/CountryActivities.htm. Accessed 21 Dec 2013.

4. Tagbo B, Uleanya ND, Nwokoye IC, Eze JC, Omotowo IB. Mothers'knowledge, perception and practice of childhood immunisation in Enugu. Nigerian Journal of Pediatrics. 2012;39(3):90-6.

5. Kunle-Olowu A, Kunle-Olowu E, Ugwu M. Immunisation coverage of antenatal and immunisation clinics attendees in the Niger Delta University Teaching Hospital. J Public Health Epidemiol. 2011;3(3):90-3. 392.

6. Antai D. Inequitable Childhood immunisation in Nigeria: A multilevel analysis of individual contextual determinants. BMC Infect Dis. 2009;9:181-5. http://dx.doi.org/10.1186/1471-2334-9-181.

7. Abdulraheem IS, Onajole A, Jimoh A. Reasons for incomplete vaccination and factors for missed opportunities among rural Nigerian children. J Public Health Epidemiol. 2011;3(4):194-203.

8. National Population Commission (NPC) [Nigeria] and ICF Macro. Nigeria Demographic and Health Survey 2008. Abuja, Nigeria: National Population Commission and ICF Macro; 2009.

9. Odusanya O, Alufohai JE, Muerice FP, Ahonkhai VI. Determinants of vaccination coverage in rural Nigeria. BMC Public Health. 2008;8:381.

10. Adebayo $B$, Oladokun $R$, Akinbami F. Immunisation coverage in a rural community in Southwestern Nigeria. J Vaccines Vaccine. 2012;3(143):3-6. 
11. Federal Republic of Nigeria 2006. Population and Housing Census, Priority Table, Volume III, Population Distribution, By Sex, State, LGA \& Senatorial District. Abuja, Nigeria: National Population Commission; 2010. http://www.population. gov.ng/images/NPCNEW/Pr\%20Vo|\%203\%20Pop\%20by\%20State\%20\&\%20 Senatorial\%20District.zip. Accessed 15 Nov 2013.

12. World Health Organization. Immunisation, Vaccines and Biologicals Immunisation Coverage Cluster Survey. Geneva, Switzerland: WHO Document Production Services; 2005 - Reference manual; WHO/IVB/04.23.

13. Gidado S, Nguku P, Biya O, Waziri NE, Mohammed A, Nsubuga P, et al. Determinants of routine immunization coverage in Bungudu, Zamfara State, Northern Nigeria, May 2010. Pan Afr Med J. 2014;18(Supp 1):9. doi:10.11604/pamj.supp.2014.18.1.4149

14. Etana B, Deressa W. Factors Associated with complete immunisation coverage in children aged 12-23 Months in Ambo Woreda, Central Ethiopia. BMC Public Health. 2012;12:566

15. Sebahat T, Nadi B. Vaccination coverage and reasons for non-vaccination in a district of Istanbul. BMC Public Health. 2006;6:125.

16. Fatiregun A.A, Adebowale AS, Ayoka RO, and Fagbamigbe AF. Assessing full immunisation coverage using lot quality assurance sampling in urban and rural districts of Southwest, Nigeria. Trans R Soc Trop Med Hyg 2013, 1-10. doi:10.1093/trstmh/trt079

17. Fatiregun AA, Okoro A. Maternal determinants of complete child immunisation among children aged 12-23 months in southern district of Nigeria. Vaccines. 2012:30:730-6.

18. Mosiur R, Sarker O. Factors affecting acceptance of complete immunisation coverage of children under five years in rural Bangladesh. Salud Publica Mex. 2010;52(2):134-40.

19. Oluwadare C. The social determinants of routine immunisation in Ekiti State, Nigeria. Ethno Med. 2009;3(1):49-56.

20. Bbaale E. Factors influencing childhood immunisation in Uganda. J Health Popul Nutr. 2013;31(1):118-20.

21. Manjunath U, Pareek RU. Maternal knowledge and perceptions about the routine immunisation programme- a study in a semi urban area in Rajasthan. Indian J Med Sci. 2003;57(4):158-63.

22. Jagrati VJ, Caroline DS, llesh VJ, Gunnar B. Risk factors for incomplete vaccination and missed opportunity for immunisation in rural Mozambique. BMC Public Health. 2008:8:161. doi:10.1186/1471-2458-8-161.

\section{Submit your next manuscript to BioMed Central and we will help you at every step:}

- We accept pre-submission inquiries

- Our selector tool helps you to find the most relevant journal

- We provide round the clock customer support

- Convenient online submission

- Thorough peer review

- Inclusion in PubMed and all major indexing services

- Maximum visibility for your research

Submit your manuscript at www.biomedcentral.com/submit 